\title{
THE IRRATIONAL BELIEFS OF BALINESE FEMALE OFFICE WORKERS
}

\author{
SUSY PURNAWATI*, INTEN DWI PRIMAYANTI IDA, ADIPUTRA IN
}

\author{
Department of Physiology, Faculty of Medical School, Udayana University, Bali, Indonesia. Email: s_purnawati@yahoo.com
} Received: 01 February 2020, Revised and Accepted: 11 March 2020

\begin{abstract}
Objective: This preliminary study aimed to explore the score of irrational beliefs (IBs) among Balinese female office workers in Gianyar. This is a new and very interesting issue in occupational mental health practice in Bali and Indonesia. The finding of this study will be able to use as information for an authority to create some program improvement for human resources at work setting.
\end{abstract}

Methods: This study used a cross-sectional study design involved 30 participants. In this study, we measured the IBs score by self-reported questionnaire of the smith IB inventory which contained 24 items statement.

Results: The means age of participants was 40.4 years old and means the length of stay was 15.2. years. In this preliminary study, we found the means score of IBs score was $52.37 \pm 10.460$ (high score category).

Conclusion: The score of IBs of Balinese female office workers in Gianyar was high score category. This result has a clinical impact as well as the outcome of this study can be used to be a recommendation to the government or organization to create an awareness program to decrease worker's IBs score in purposing better their mental health, work productivity, and well-being.

Keywords: Balinese female office worker, Irrational beliefs, Mental health

(C) 2020 The Authors. Published by Innovare Academic Sciences Pvt Ltd. This is an open access article under the CC BY license (http://creativecommons. org/licenses/by/4. 0/) DOI: http://dx.doi.org/10.22159/ajpcr.2020.v13i5.37093

\section{INTRODUCTION}

Balinese women are generally described as hardworking and fight women. In Hindu culture's life, ceremony preparation work is also covering Balinese office woman life. This activity is done beside their main job at the office. Because they feel that all the responsibility is on their hands. It is irrational if they understand their resources. According to their belief system, they need to find many supporting systems for their health, productivity, and well-being.

In daily life, often, it can be seen that Balinese women take jobs such as men, working as carrying heavy load overhead at traditional markets, sand carriers, or in the past, we often see scenes of old grandmothers carrying firewood walking a distance of many kilometers. In traditional celebrations, we can also see women with a high offering overhead. Modern Balinese women today must be able to multitask. When they have to go home late at night after completing work at the office, Balinese women must be able to complete household jobs, ceremonies preparation, and caring for children. Moreover, Balinese women also have to set aside time for social activity in Banjar or even just me-time like some fascial treatment in a salon or exercise in a fitness center [1]. There is also, nowadays, where Balinese women also take on the role of office workers in line with the roles they must carry out. If there is an imbalance of their high workload and responsibility within supported by good psychological conditions, result in a risk decreased work performance and productivity, moreover, to impact on workers' health.

An irrational belief (IB) is a new issue and very important to explore among workers in Indonesia, so this study is the first study in Bali which explores the score of IBs. Moreover, many studies found that there is any relationship between IBs with psychological distress. IBs which are a Person's irrational perception or his/her view of an event will have consequences for their behavior and emotional condition. This means that the consequences are not a direct result of the events experienced but are caused by belief systems [2]. It is in line with Sudrajat, who clearly illustrates the ABC theory from Ellis $[3,4]$. This theory emphasizes that problematic behavior caused by one's thoughts, namely irrational thoughts, so the focus of handling on this approach is on the individual's thinking and focuses on how humans think, judge, decide, analyze, and act. The key concepts of the theory inform about three pillars that build individual behavior, namely, antecedent event $(A)$, belief (B), and emotional consequence (C). Antecedent event (A), namely, all external events experienced or exposed to individuals, belief (B) the views, values, or self-verbalization of an individual on an event, and the emotional consequence $(\mathrm{C})$ is a consequence as a result or reaction of individuals in the form of feelings of pleasure or emotional barriers concerning the antecedent event (A) [3]. The person with IBs thinks that the world or every event must be as perfect as their beliefs and everyone should always love one each other. They will easy to feel fail to achieve their goal and become distressed.

According to the negative impact of the IBs among workers, we conducted this study to find the novelty and to answer the research questions as follows: How high is the score of the IBs of Balinese female office workers in Gianyar?

\section{METHODS}

\section{Study participants}

This study was a preliminary study within the cross-sectional study design held in mid of April 2019. As preliminary data, 30 female participants (which was selected by consecutive sampling technique) of office workers in Gianyar of Bali Province were involved. They were representing government and private office workers in the City of Gianyar, Ubud, and South Gianyar (Blahbatuh village).

\section{RESULTS AND DISCUSSION}

The marital status of female office workers has any role for housework burden among them, especially female workers with children more than two. Addis and Bernard found that self-downing and the need for comfort were the dimensions of irrational thinking most strongly related to marital dysfunction [4]. The marital status of Balinese female 
office workers who were involved in this study was mostly married, which can be seen in Table 1 . Only 7 workers were un-married.

Table 2 shows that the mean ages of participants were 40.4 years old and the length of stay was 15.2 years. The main result of this preliminary study found that the means score of IBs among 30 Balinese female office workers was $52.37 \pm 10.460$. This score shows in a high score category.

The main findings of this study indicate that the mean score of IBs among female office workers in Gianyar is a high category. This illustrates that any concern is needed for workers and policymakers who involve in a human resource empowerment program of the region. The high score of IBs among workers in Gianyar can have an impact on increasing the risk of mental health problems among them and also has an impact to work performance. If comparing with the previous study shows that a person with a high score of IBs tends to perfectionism and related cognitive-behavioral problems such as anxiety [5]

According to Sudrajat and Ellis, one's emotional reactions are mostly caused by conscious and unconscious evaluations, interpretations, and philosophies. Psychological or emotional barriers are the result of irrational and irrational ways of thinking. Emotions accompany individuals who think with prejudice, are very personal and irrational. Theoretically, humans fundamentally tend to think rationally and irrationally. When thinking and behaving rationally, humans will be effective, happy, and competent. When they are irrational in thinking and behaving, it becomes ineffective. Thinking irrational begins with learning illogically obtained from parents and the culture in which they were grown. Irrational thinking will be reflected in the verbalization used. Illogical verbalization shows the wrong way of thinking and the right verbalization shows the right way of thinking. Negative feelings and thoughts and self-rejection must be resisted by rational and logical thinking, which can be accepted according to common sense $[3,6]$.

The role of IBs on emotions and behavior can be explained through biopsychological theory related to the involvement of the limbic area of the brain. An emotional center which is located in the limbic system of the brain is easily stimulated by perceptions of unsuitable expectations or conditions known as a stressor. This can result from psychological distress experiences and related to the risk of being suffered from some illness among the person. The higher the IB results in easily on being decreased in work efficiency or productivity [7-11]. Sure, this does not signify that workers must only passively accept the condition. There are several studies that show that many strategies, as well as cognitive restructuring, are effective at changing the belief systems, and increasing cognitive behavioral skills of a person can reduce anxiety [12-14]. One example of IB is "the idea that we must have certain and perfect control over things," could be replaced with thinking to be more positive as "the world is full of improbability and chance and that we can still enjoy life despite this" to reduce psychological distress [14], and there is also any finding

Table 1: Marital status of Balinese female office workers

\begin{tabular}{lll}
\hline Variable & Frequency & Percent \\
\hline Married & 23 & 77.7 \\
Un-married & 7 & 23.3 \\
\hline
\end{tabular}

Table 2: Age and length of stay of Balinese female office workers

\begin{tabular}{llllll}
\hline & $\mathbf{n}$ & Minimum & Maximum & Mean & $\begin{array}{l}\text { Std. } \\
\text { deviation }\end{array}$ \\
\hline Age & 30 & 20.0 & 57.0 & 40.4 & 11.640 \\
Length of Stay & 30 & 1.0 & 38.8 & 15.2 & 10.489 \\
Irrational & 30 & 38.0 & 70.0 & 52.37 & 10.460 \\
Beliefs score & & & & & \\
\hline
\end{tabular}

that hardiness person fells despite the conditions under stress with their rational beliefs dominantly stay physically and psychologically healthy $[15,16]$. In changing IB to rational beliefs is one method to improve someone's coping mechanism (where the term of coping is a part of a person-environment transaction that occurs when an individual appraises a situation as stressful) and an effect on their personality constructs $[6,14,16]$.

The source of stress among Balinese female office workers is mainly the overload of in a combination work burden at workplace and housework which is added by the complexity of Hindu's ceremony preparation. When they have a stressor from work burdens that combine with their IB, cognitive performance will decrease and affect their behavior and ability to make decisions. Perfectionism construct which is accompanied by perceptions of social conditions and a person's ability if combine with the role of IB will also increase psychological distress [17]. IB is a background of the response to the performance of tasks and making different cognitive functions among workers [18]. That is the reason how cognitive restructuring is effective to change the IBs of workers to be more rational beliefs.

The mean score of IBs in this preliminary study is $52.37 \pm 10.460$, so we categorize the score as a high score with an indication to get attention for workers. Adequate strategies are needed to carry out awareness programs aimed at socializing the impact of IBs on mental health conditions and on work productivity followed by counseling programs or building capacity training so that workers have the adequate individual capacity in carrying out their roles as resilient Balinese women, healthy, and have high work productivity.

IBs correlate significantly and positively to stress, where beliefs are not rational as mediators in the relationship between stressors and stress. Stress disturbs the homeostatic equilibrium of the body and makes individuals susceptible to diseases [19] and also in line with a theory that there is the link between the continuing development of heart disease and depression with chronic stress [20]. The high IBs score of Balinese women can not only result in decreased work productivity but can also result in an increased risk of chronic stress, depression, and even suicide. Since IBs are beliefs that could make them fail to achieve personal goals, irrational, and unrealistic. Persons with IBs show a different perspective on themselves, real stressors, and the world they face. Those could create of increase a tendency to feel distressed and being hopeless [20,21].

\section{CONCLUSION}

In the conclusion of this preliminary study, there is a high score of IBs among Balinese female workers in Gianyar. In the future, more research is needed, especially with some program or intervention to educate participants to have more rational beliefs and decrease their IBs to find its effect in reducing psychological distress or another risk of illness parameter.

\section{ACKNOWLEDGMENT}

We are from the research team offer sincere thanks to Witarti Luhkiati and Anak Agung Widya for the assistance given to us during data collecting in this study.

\section{AUTHORS' CONTRIBUTIONS}

We declare that this work was done by the authors named in this article and all liabilities about claims relating to the content of this article will be borne by the authors. Dr. I Dewa Ayu Inten Dwi Primayanti, M. Biomed., Physiology Department, Medical Faculty of Udayana University, assisted in organizing data. Professor Dr. dr. I N Adiputra, PFK., MOH., guided the manuscript preparation and reviewed the manuscript.

\section{CONFLICTS OF INTEREST}

The author declares no conflicts of interest. 


\section{FUNDING SOURCE}

This research was fully funded by the grant of Research and Community Service Unit of the Udayana University block grant of 2018/2019. No other funding resources.

\section{REFERENCES}

1. Wirartha. Balinese Women in the Current Era. (In Indonesian Lang.). Bali Post; 2019. Available from: http://www.balipost.com/ news/2019/04/11/72756/perempuan-bali-masa-kini.html. [Last accessed on 2019 Sep 15].

2. David D, Lynn SJ, Ellis. A. Rational and Irrational Beliefs: Research, Theory, and Clinical Practice. New York: Oxford University; 2009.

3. Sudrajat. Rational Emotive Counseling (RET). (In Indonesian Lang.); 2019. Available from: https://www.akhmadsudrajat.wordpress.com. [Last accessed on 2019 Jul 10].

4. Addis J, Bernard, ME. Marital adjustment and irrational beliefs. J Ration Emot Cogn Behav Ther 2002;20:3-13

5. Ellis A. The role of irrational beliefs in perfectionism. In: Flett GL, Hewitt PL, editors. Perfectionism: Theory, Research, and Treatment. United States: American Psychological Association; 2002. p. 217-29.

6. Ellis A. Rational emotive behavior therapy. In: Dumont F, Corsini RJ, editors. Six Therapists and One Client. New York: Springer; 2000. p. 85-143.

7. Popov S, Popov B, Damjanovie R. The role of stressors at work and irrational beliefs in the prediction of teacher's stress. Primenjena Psichol 2015;8:5-23.

8. Mahfar M, Noah SM, Jaafar WM, Shah IM, Ahmad J. The relationship between irrational belief system and stress among fully residential school students in Johor. J Teknol 2012;59:115-23.

9. Mahfar M, Xian KH, Ghani FA, Kosnin A, Senin AA. Irrational beliefs as a mediator in the relationship between activating event and stress in Malaysian fully residential school teacher. Can Cent Sci Educ 2018;14:21-8.

10. Küçük L, Gur K, Şener N, Boyacıoğlu NE, Çetindağ Z. Correlation between irrational beliefs and the depressive symptom levels of secondary school children. Int J Caring Sci 2016;9:99.

11. Bernard ME. Teacher Beliefs and Stress. New York: Springer Publishing Company, Inc.; 2016.

12. Nezu AM. Differences in psychological distress between effective and ineffective problem solvers. J Couns Psychol 1985;32:135-8.

13. Shimazu A, Kosugi S. Job stressors, coping, and psychological distress among Japanese employees: An interplay between active and nonactive coping. Work Stress 2003;17:38-51.

14. Skirka N. The relationship of hardiness, sense of coherence, sports participation, and gender to perceived stress and psychological symptoms among college students. J Sports Med Phys Fitness 2000;40:63-70.

15. Deckro GR, Ballinger KM, Hoyt M, Wilcher M, Dusek J, Myers P, et al. Evaluation of a mind/body intervention to reduce psychological distress and perceived stress in college students. J Am Coll Health 2002;50:281-7.

16. Andreas V, Christoph F, Martin GF, David D. Irrational beliefs and psychological distress: A meta-analysis. Psychother Psychosom 2016;85:8-15.

17. Paul LH, Gordon LF. Perfectionism in the self and social contexts: Conceptualization, assessment, and association with psychopathology. J Pers Soc Psychol 1991;60:456-70.

18. Matthews G, Campbell SE, Falconer S, Joyner LA, Huggins J, Gilliland $\mathrm{K}$, et al. Fundamental dimensions of subjective state in performance settings: Task engagement, distress, and worry. Emotion 2002;2:315-40

19. Sarjan HN, Yajurvedi HN. Efficacy of an active compound of the herb, ashwagandha in the prevention of stress-induced hyperglycaemia. Int J Pharm Pharm Sci 2018;10:44-9.

20. Ahmed M, Morrissey H, Ball PA. Mental ill-health and heart failure comorbidity. Int J Curr Pharm Res 2019;11:11-7.

21. DiLorenzo TA, David D, Montgomery GH. The interrelations between irrational cognitive processes and distress in stressful academic settings. Pers Ind Differ 2007;42:765-76. 